\title{
Optimization of Culture Conditions to Improve PHB Production of Methane-Utilizing Mixed Culture
}

\author{
Wei Zhang, a , Qiannan Wang ${ }^{2, b}$ and Jiaying $\mathrm{Xin}^{3, \mathrm{c}^{*}}$ \\ $1,2,3^{\star}$ Key Laboratory for Food Science and Engineering, Harbin University of Commerce, China

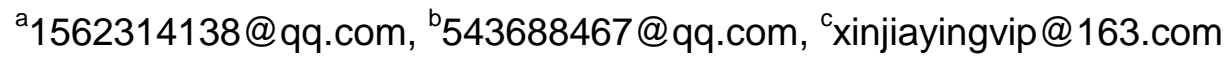

Keywords: Poly- $\beta$-hydroxybutyrate (PHB); Methane-utilizing mixed culture; Methanotrophic bacteria; High cell density

\begin{abstract}
Poly- $\beta$-hydroxybutyrate (PHB) can be produced by various species of bacteria as carbon and energy storage materials. This biopolyester has attracted increasing attentions as biodegradable plastics not only for its similar material properties to conventional plastics but also for its biodegradable properties. PHB has thermoplastic, can be used for food packaging film bag, packaging lining layer for drinks and fresh food tray, etc. Furthermore, PHB has lower oxygen and moisture permeability, which is benefit for food storage and transportation, so that it has a broad application prospect in the field of food packaging. In this peper, Methane-utilizing mixed culture with a high PHB storage capacity was gained from the biogas soil at DA Qing oil field as enriching source after domestication with the approach of the aerobic dynamic feeding (ADF, feast-famine condition). The community structure of Methane-utilizing mixed culture and the catalytic performance of the heterotrophs and methanotrophic bacteria isolated from the mixed culture were investigated. By adjusting the medium concentration of several important nutrients. Optimized medium suitable for cell growth in the first stage and second stage of cellular accumulation of PHB were obtained. By optimizing the supply of carbon sources and the composition of the culture medium, high cell density and yield of PHB can be obtained.
\end{abstract}

\section{Introduction}

Commercial production of PHB is currently based on pure culture processes employing either natural PHB producers or genetically modified bacteria. Pure culture processes use generally pure sterile substrates and axenic reactors, leading to high production costs and thus relatively expensive products, which have prevented the use of this material on a real industrial scale, especially in the field of food packaging.

Methane-utilizing mixed culture grows with the methane and has the ability to accumulate PHB in an open condition. Recent studies have reported in this area [1,2]. This bacteria can use in an open condition with cheap methane as a carbon source and achieve continuous production of PHB .This bacteria can reduce production costs and bring certain economic benefits. Methane oxidizing bacteria in the mixed culture is dominant bacteria, which can accumulate PHB [3, 4].

Factors affecting cell growth and PHB accumulation include growth environment of carbon, nitrogen, nutrients needed for growth, the accumulation of the growth inhibitor in fermentation process $[5,6]$. These factors directly or indirectly affect catabolism and assimilation process of PHB synthetic cells. Therefore, in this paper, methane oxidation mixed culture with higher PHB storage capacity was optimized by culture medium to further improve the growth in the first phase and the PHB production in second phase. In this paper, some important nutrients for cell growth and PHB accumulation has been optimized.

\section{Experimental Material and Experimental Method}

Strain and Medium Composition. Methane-utilizing mixed culture is obtained at methane-rich area of Daqing Oilfield in Heilongjiang Province from the soil by methane as sole carbon source. 
The experiments were carried out in a mineral salt medium, and the medium constituents were with the following compositions $(\mathrm{g} / \mathrm{L})$ :

$$
\text { A: } \mathrm{NH}_{4} \mathrm{Cl}(0.5), \quad \mathrm{KH}_{2} \mathrm{PO}_{4}(0.4), \mathrm{K}_{2} \mathrm{HPO}_{4}(0.49), \mathrm{CaCl}_{2} \cdot 2 \mathrm{H}_{2} \mathrm{O}(0.024), \mathrm{MgSO}_{4} \cdot 7 \mathrm{H}_{2} \mathrm{O}(0.3) \text {, }
$$
$\mathrm{NaCl}(0.3), \mathrm{KNO}_{3}(1.6)$

$\mathrm{B:} \mathrm{CuSO}_{4} \cdot 5 \mathrm{H}_{2} \mathrm{O}\left(4 \times 10^{-3}\right), \mathrm{FeSO}_{4} \cdot 7 \mathrm{H}_{2} \mathrm{O}\left(4 \times 10^{-3}\right), \mathrm{MnSO}_{4} \cdot 5 \mathrm{H}_{2} \mathrm{O}\left(4 \times 10^{-4}\right), \mathrm{ZnSO}_{4}(3.4 \times$ $\left.10^{-4}\right), \mathrm{NaMoO}_{4} \cdot 2 \mathrm{H}_{2} \mathrm{O}\left(2.4 \times 10^{-4}\right)$.

Culture Method. 250mL shake flask fitted 100mL sterilized inorganic salt medium. Under open conditions (culture are exposed naturally environment). $10 \%$ of bacteria was inoculated; Culturing with $30{ }^{\circ} \mathrm{C}$ constant temperature air bath and 180rpm; The culture atmosphere, $\mathrm{V}_{\text {(methane) }}$ : $\mathrm{V}_{\text {(air) }}=1: 1$; the culture time: 96-144h; changing gas for the cultured bacteria every $24 \mathrm{~h}$.

The Effect of Different Nutrients on Cell Growth and PHB Accumulation. The media components of first stage adapted to cell growth (nutritional balance stage) was optimized. After culturing the cells in the first stage $120 \mathrm{~h}$ optimized medium, transferring the above-mentioned one component into a medium of different concentrations for the second phase of culturing. Examining production of PHB to select the appropriate concentration increased second phase (phase nutrition restricted) intracellular accumulation of PHB. In order to accurately investigate influence on cell growth and PHB accumulation ability of each of the components, using the approach of keeping the concentration of other components constant and treating only the concentration of the components examined changes.

Extraction of PHB. The appropriate amount of surfactant (betaine), chelates (EDTA disodium salt) and cells (maintained surfactant (betaine): chelates (EDTA disodium salt): dry cell weight was 0.12: 0.08: 1), was dissolved in 50mL of deionized water. $\mathrm{PH}$ adjustment $5 \mathrm{~mol} / \mathrm{L}$ of $\mathrm{NaOH}$. Under the conditions of $\mathrm{pH}=13$ at $50^{\circ} \mathrm{C}$ at a rotational speed of $1200 \mathrm{rpm}$ were treated cells broken $20 \mathrm{~min}$. The ionized water and washed with acetone each spent time in the oven temperature at $70^{\circ} \mathrm{C}$ drying sediment obtained by centrifugation.

Determination of Cell PHB with Concentrated Sulfuric Acid. PHB with concentrated sulfuric acid upon heating can be quantitatively converted to crotonic acid. Crotonic acid at $235 \mathrm{~nm}$ with a maximum absorption peak. By UV spectrophotometer measure $\mathrm{OD}_{235}$ value determines the amount of PHB. The extracted PHB dried and concentrated sulfuric acid. $100^{\circ} \mathrm{C}$ water bath heated reaction $10 \mathrm{~min}$. Cooled to room temperature.

\section{Results and Discussion}

The Effect of Nitrogen on Cell Growth and PHB Accumulation. Nitrogen is a constituent substance or metabolites of microbial cells nitrogen source [7]. Limiting nitrogen source and increasing the ratio of carbon and nitrogen induce into the PHB cycle acetyl CoA key enzyme - $\beta$ one thiolase activity increased, and less induced into the TCA cycle acetyl-CoA citrate synthase activity high.

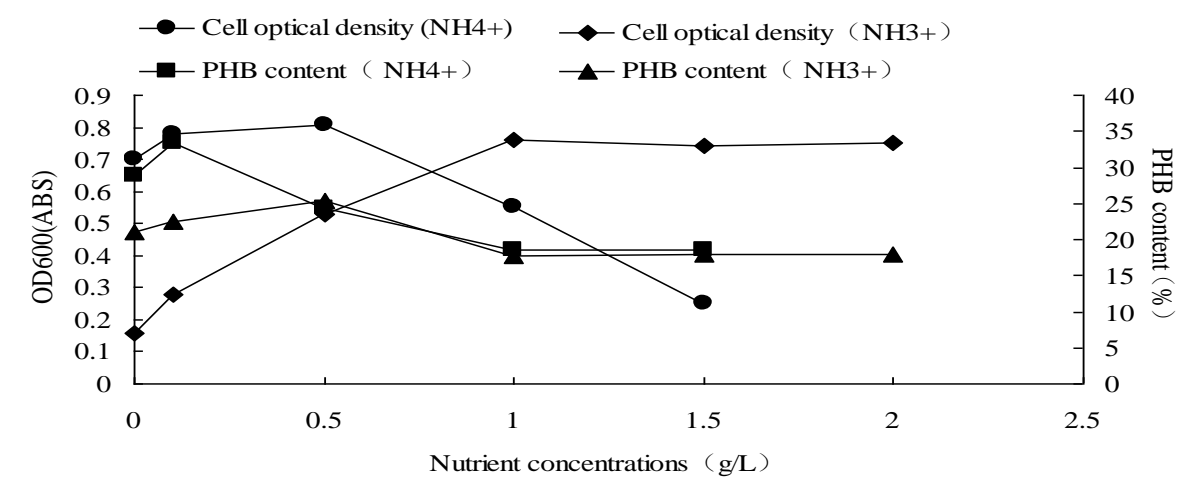

Figure 1. Effects of NH4+ and NO3- on biomass and PHB accumulation $(n=3)$ 
This figure demonstrates that the effect of nitrogen on methane oxidizing bacteria mixed cell growth and PHB accumulation of significant results showed that high concentrations of $\mathrm{NH}_{4}{ }^{+}$on growth and PHB accumulation of cells are inhibited, probably due to $\mathrm{NH}_{4}{ }^{+}$with the same active competition MMO of methane site, high $\mathrm{NH} 4+$ will inhibit methane absorption rate. Reported in the literature $[8,9]$, as $\mathrm{NH}_{4}{ }^{+}$oxidation product obtained in the first hydroxyethyl ammonium $\left(\mathrm{NH}_{2} \mathrm{OH}\right)$ when concentrations as low as $0.1 \mathrm{mM}$ when MMO has reversible inhibitory effects and easy by the hydroxyl ammonium produced also by $\mathrm{NO}_{2}^{-}$inhibition of NADH and formate dehydrogenase catalyzes the production of cell growth and PHB accumulation have a negative impact. The figure shows when the $\mathrm{NH}_{4} \mathrm{Cl}$ concentration of less than $0.3 \mathrm{~g} / \mathrm{L}, \mathrm{OD}_{600}$ has large value. Indicating that a large amount of $\mathrm{NH}_{4}{ }^{+}$methane oxidizing bacteria inhibit oxidation of methane, but a small amount of $\mathrm{NH}_{4}{ }^{+}$can stimulate the growth of methane-oxidizing bacteria.

Can be seen from the figure, the growth of the mixed methane-oxidizing bacteria $\mathrm{OD}_{600}$ value increases with increasing concentration of $\mathrm{KNO}_{3}, \mathrm{OD}_{600}$ value and high content of PHB respectively 0.688 and $19.62 \%$ when KNO3 concentration of $0.5 \mathrm{~g} / \mathrm{L}$. Continued to increase KNO3 concentration, $\mathrm{OD}_{600}$ value continues to increase, but PHB content decreased. KNO3 don't have inhibitory effect on cell growth. Mixed methane-oxidizing bacteria more appropriates of carbon, because of the mixed methane-oxidizing bacteria in the methane-oxidizing bacteria dominant strains are strictly aerobic bacteria, the need for a high redox potential. $\mathrm{KNO}_{3}$ compared $\mathrm{NH}_{4} \mathrm{Cl}$ having a relatively high redox potential ${ }^{[10]}$ so that $\mathrm{KNO} 3$ is a role in promoting cell growth while limiting nitrogen high nitrogen ratio $(\mathrm{C} / \mathrm{N})$ conducive to the accumulation of $\mathrm{PHB}$.

The Effect of Phosphorus on Cell Growth and PHB Accumulation. $\mathrm{KH}_{2} \mathrm{PO}_{4}$ and $\mathrm{K}_{2} \mathrm{HPO}_{4}$ medium not only provide a microbial cell growth needed source of phosphorus, but also the microorganism to provide a buffer system to maintain the balance of the medium and other mineral elements and stable environment conducive to effective microorganisms for nutrients uses. However, high concentrations of phosphorus inhibit the oxidation of methanol to formaldehyde dehydrogenase catalyzed methanol. Studies have shown that phosphorus concentrations exceeding $40 \mathrm{mM}$ inhibit the cell growth [11].

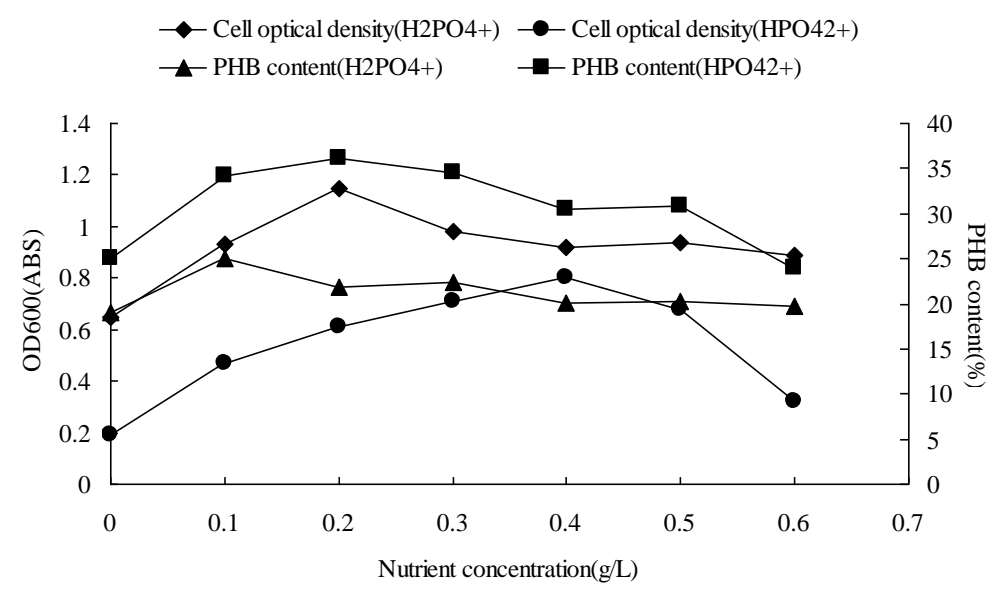

Figure 2. Effects of $\mathrm{H} 2 \mathrm{PO} 4+$ and $\mathrm{HPO} 42+$ on biomass and PHB accumulation $(\mathrm{n}=3)$

Data can also be seen from the graph, an important source of phosphorus nutrients as cell growth, one of the cell growths and PHB accumulations have the same effect as a nitrogen source. Within a certain range, when $\mathrm{KH}_{2} \mathrm{PO}_{4}$ is a relatively high concentration so that cell growth can provide positive momentum and low concentrations of $\mathrm{KH}_{2} \mathrm{PO}_{4}$ is conducive to the synthesis of PHB. The study found that low concentrations of $\mathrm{HPO}_{4}{ }^{2-}$ did not promote the accumulation of PHB, also on cell growth is also negative because $\mathrm{HPO}_{4}{ }^{2-}$ in the medium accounted for a larger proportion. The concentration changes a great impact on the environment $\mathrm{pH}$. Concentration is too low to make the medium $\mathrm{pH}$ acidic. Cells are not well adapted to survive the acidic environment resulting in decreased cell growth. To some extent, reducing the accumulation of PHB. 
The Effect of Magnesium on cell Growth and PHB Accumulation. $\mathrm{Mg}^{2+}$ is activator of certain enzymes such as hexokinase, isocitrate dehydrogenase, carboxylase and nitrogenase enzyme. $\mathrm{Mg}^{2+}$ also play a role stabilizing ribosomes, cell membranes and nucleic acids.

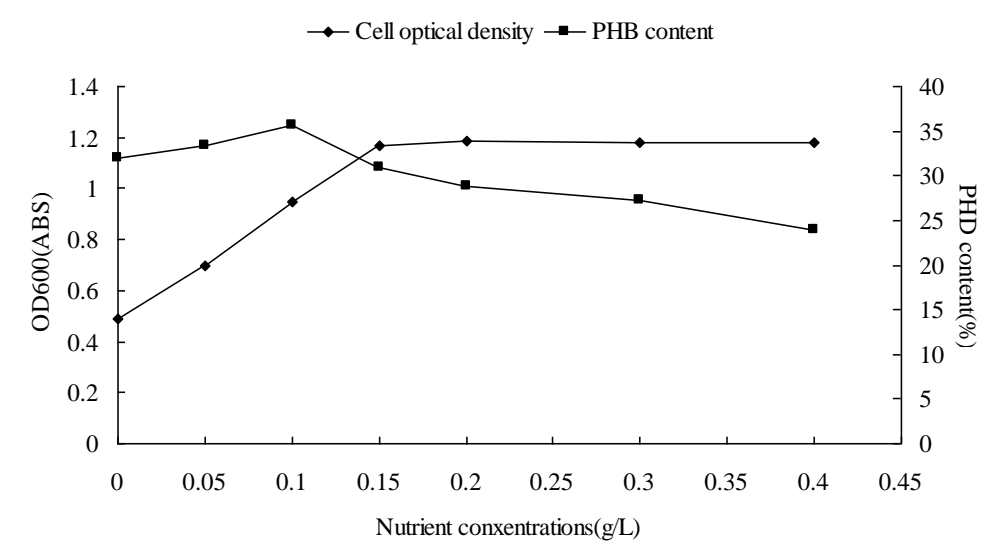

Figure 3. Effects of $\mathrm{Mg} 2+$ on biomass and PHB accumulation $(\mathrm{n}=3)$

K.-D. Wendlandt et al. [12, 13] reported $\mathrm{Mg}^{2+}$ as nutrients at low and high concentrations respectively played the same role with nitrogen. Data on the map prove this conclusion. It is reported that the Methylosinus trichosporium OB3b by controlling the concentration of $\mathrm{Mg}^{2+}$ to product PHB. PHB content can reach $40 \%$ and for methane oxidation mixed bacteria, can also be used to improve the regulation of $\mathrm{Mg}^{2+}$ content of PHB. When the concentration of $\mathrm{Mg}^{2+}$ in $0.15-0.25 \mathrm{~g} / \mathrm{L}$ range, cell growth favorable. In 0.05-0.15g / L range, cells accumulate PHB advantageous. $\mathrm{Mg}^{2+}$ concentration regulation for improving the yield of PHB also has an important role.

The Effect of Copper and Iron on Cell Growth and PHB Accumulation.

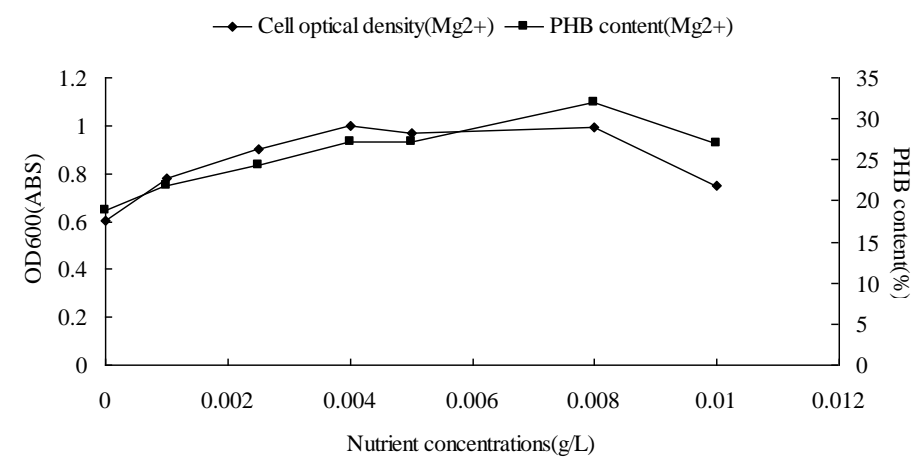

Figure 4. Effects of $\mathrm{Cu} 2+$ on biomass and PHB accumulation $(\mathrm{n}=3)$

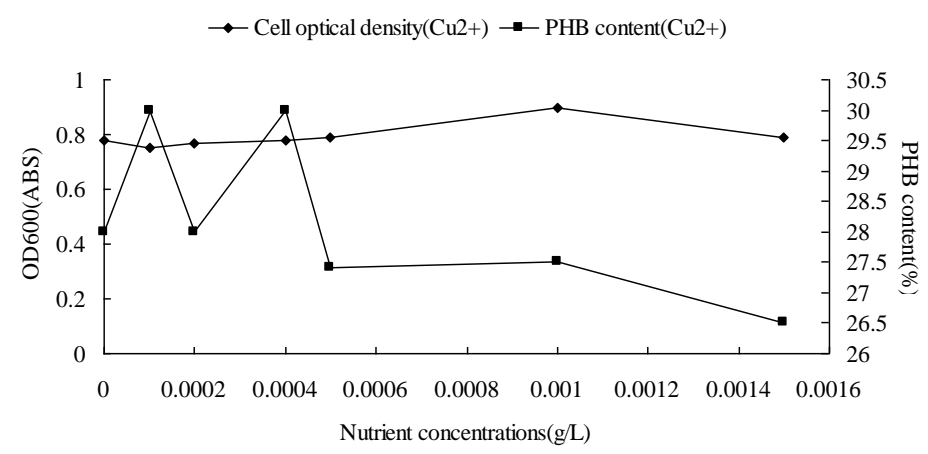

Figure 5. Effects of $\mathrm{Fe} 3+$ on biomass and PHB accumulation $(\mathrm{n}=3)$ 
As can be seen from the results in Fig, It was found $\mathrm{Cu}^{2+}$ concentration is about $0.008 \mathrm{~g} / \mathrm{L}$ to maintain optimal cell growth and metabolism and accumulation of PHB. High concentrations of $\mathrm{Fe}^{3+}$ $\left(>4 \times 10^{-4} \mathrm{~g} / \mathrm{L}\right)$ cells accumulate PHB has a certain extent. There was the highest accumulation of PHB when concentration was $2.0 \times 10-4 \mathrm{~g} / \mathrm{L}$. MMO is characterized enzymes of methane oxidizing bacteria Methane reaction. Soluble methane monooxygenase (sMMO) contains a hydroxylase (sMMOH). sMMOH is a dimer composed of three subunits $(a \beta \gamma)_{2}$. Each monomer has a dual-core Fe active site. Located hydroxylase $\alpha$ subunit, which is the active site of the methane oxidation. Therefore, the presence of Fe can stimulate play sMMO activity [14].

\section{References}

[1] J. Helm, K.-D. Wendlandt, M. Jechorek, U. Stottmeister, Potassium deficiency results in accumulation of ultra-high molecular weight poly-b-hydroxybutyrate in a methane utilizing mixed culture, J. Appl. Microbiol. 2008, 105: 1054 1061 Reference to a book:

[2] J. Helm, K. D. Wendlandt, G. Rogge, U. Kappelmeyer, Characterizing a stable methane-utilizing mixed culture used in the synthesis of a high-quality biopolymer in an open system, J. Appl. Microbiol. 2006, 101: 387 395

[3] Du G., Chen J., Yu J., Lun S. Continuous production of poly-3-hydroxybutyrate by Ralstonia eutrophus in a two-stage culture system. J. Biotechnol., 2001b, 88: 59 65

[4] Yamane T. Cultivation engineering of microbial bioplastics production. FEMS Microbiol. Rev., 1992, 103: 257 264

[5] Min Hang, Chenzhong Yun, Chen Meici paddy soil methane oxidation activity and environmental factors affecting soil Research] 2002, 39 (5): 687 - 692

[6] Chenzhong Yun, Min Hang rice - Different soil ion activity of methane oxidization in a paddy rice Plant Nutrition and Fertilizer Science. 2002, 8 (2): 219 - 223

[7] Hubley, J.H., Thomson, A.W., and Wilkinson, J.F. Specific inhibitors of methane oxidation in Methylosinus trichosporium. Arch. Microbiol. 1975, 102 (3): 199 202

[8] King, G.M., and Schnell, S.. Ammonium and nitrite inhibition of methane oxidation by Methylobacter albus BG8 and Methylosinus trichosporium OB3b at low methane concentrations. Appl. Environ. Microbiol. 1994,60 (10): 3508 3513

[9] Bedard C., Knowles R. Physiology, biochemistry, and specific inhibitors of CH4, NH4+and CO oxidation by methanotrophs and nitrifers. Microbiol.Rev. 1989, 53: 68 84

[10]Park, S., Hanna, L.M., Taylor, R.T.and Droege, M.W.. Batch cultivation of Methylosinus trichosporium OB3b. I: Production of soluble methane monooxygenase. Biotechnol. Bioeng. 1991, 38 (4): 423 433

[11] Yu Haixia use of Microbial Technology to Control Coal Gas Zhejiang University PhD thesis 2007: 11 to 16

[12]Wendlandt K. -D., Jechorek M., Helm, J., Stottmeister U. Producing poly-3-hydroxybutyrate with a high molecular mass from methane. J. Biotechnol., 2001, 86: 127 133

[13] Tsubota J., Hasumi F., Takeguchi M., Horie S., Isobe D. Producing polyhydroxybutyrate (PHB) by culturing methane-using bacteria in culture medium with alternating levels of additive concentration with respect to PHB accumulation 2005, JP2005304484-A

[14]Fitch M. W., Speitel Jr. G. E., Georgiou G. Degradation of Trichloroethylene by Methanol-Grown Cultures of Methylosinus trichosporium OB3b PP358. Appl. Environ. Microbiol., 1996, 62: 1124 1128. 